\title{
La adición de salmeterol permite reducir los corticoides inhalatorios en pacientes con asma persistente
}

Inhaled corticosteroid reduction and elimination in patients with persistent asthma receiving Salmeterol. Lemanske RF, Sorkness CA, Mauger EA. JAMA 2001; 285: 2594-2603

\section{Objetivo}

Determinar si pueden reducirse o suprimirse los corticoides inhalatorios en pacientes con asma persistente después de agregar $\beta 2$ agonistas de acción prolongada a su esquema de tratamiento.

\section{Diseño}

Estudio clínico, aleatorizado, controlado, triple ciego (pacientes, personal del centro de salud y analistas de datos). Seguimiento de 24 semanas.

\section{Lugar}

Seis centros clínicos de asma pertenecientes al Asthma Clinical Researh Network del National Herat Lung, and Blood Institute, EE.UU.

\section{Pacientes}

Se incluyeron 175 pacientes, con edades entre 12 y 65 años, portadores de asma persistente controlada en forma subóptima con tratamiento inhalatorio con triamcinolona $(400 \mathrm{mg} 2$ veces/ día) durante 6 semanas

\section{Intervención}

Todos los pacientes continuaron recibiendo triamcinolona inhalatoria (400 $\mathrm{mg} 2$ veces/ día ) y fueron aleatorizados a recibir placebo $(n=21)$ o Salmeterol (42 mg 2 veces/día) durante 2 semanas $(n=154)$. A las dos semanas, el grupo placebo redujo la dosis de corticoide a $200 \mathrm{mg} 2$ veces/día. La mitad del grupo que recibía Salmeterol (que llamaremos salmeterol menor [SM]) fue asignada aleatorizadamente a reducir el $50 \%$ del tratamiento corticoideo inhalatorio (por 8 semanas) y luego eliminarlo (por otras 8 semanas). La otra mitad que recibía Salmeterol (que llamaremos salmeterol plus [SP] fue aleatorizada para continuar con Salmeterol y Triamcinolona en iguales dosis durante todas las 16 semanas.

\section{Medición de resultados principales}

Se definió como fallo en el tratamiento del asma en los pacientes que recibieron Salmeterol en todos estos casos: descenso del VEF1 de más del $20 \%$ con respecto al basal, disminución del 20\% del pico flujo espiratorio matinal, incremento en la utilización de medicación de rescate, concurrencia a la sala de emergencia por descompensación aguda de asma, o uso de corticoides orales o parenterales.

\section{Resultados principales}

La falla del tratamiento ocho semanas después de haber reducido la triamcinolona en el grupo SM fue del $8.3 \%$ (IC95 2\% a 15\%), mientras que en el grupo SP fue del $2.8 \%$ (IC95 0 a $7 \%$ ) en el mismo periodo (estas diferencias no fueron significativas). La falla terapéutica fue del $46 \%$ (IC95 $34-59 \%$ ) a las ocho semanas de suspender el corticoide inhalatorio en el grupo SM, comparado con el 13\% (IC95 5-22\%) del grupo SP. El riesgo relativo de falla terapéutica al final del periodo del grupo SM fue de 4.3 (IC95 2.09.2) comparado con el grupo SP.

\section{Conclusión}

Los pacientes con asma persistente controlado en forma subóptima con triamcinolona inhalatoria, pero que los síntomas mejoran con el agregado de salmeterol, pueden reducir a la mitad la dosis del corticoide inhalatorio sin una pérdida significativa del control del asma. En cambio, la supresión total de la triamcinolona si provoca un importante deterioro del control del asma.

\section{Comentario}

La inflamación de la vía aérea en el asma se produce por la participación de los eosinófilos, linfocitos activados, los mastocitos, descamación de las células epiteliales junto con la secreción de citoquinas. Todo esto da como resultado final la obstrucción de la vía aérea. Ya fue demostrado, que cuando la dosis de corticoides inhalatorios son reducidos en los pacientes con asma bien controlado, existe aumento de eosinófilos en el esputo y deterioro de la funcionalidad respiratoria. ${ }^{1}$

Este artículo confirma que los corticoides inhalatorios son sumamente útiles para el manejo del asma persistente, aunque es interesante la posibilidad de la reducción de los corticoides inhalatorios hasta en un $50 \%$ de su dosis cuando se agrega salmeterol en forma continua al tratamiento.

Varios estudios han sugerido interacciones complementarias entre los $\beta 2$ agonistas de acción prolongada y los corticoides, ya que estos últimos aumentarían las síntesis de $\beta 2$ adrenoreceptores y los $\beta 2$ agonistas estimulan en forma selectiva los receptores $\beta 2$ adrenérgicos. Otra posibilidad sería que los $\beta 2$ agonista de acción prolongada actuarían sobre las células epiteliales mejorando la resistencia a la injuria y además la utilización de ambos contribuiría a la remodelación de la vía aérea.2

Por el momento el mayor énfasis en el tratamiento del asma está centrado en controlar la inflamación de la vía aérea especialmente con los corticoides inhalatorios. El agregado de $\beta 2$ agonistas de acción prolongada es una estrategia razonable en los pacientes con asma persistente, sobre todo si podemos reducir la dosis de corticoide inhalatorio.

Dra. Alicia de la Canal [ Sección Neumonología. Servicio de Clínica Medica. Hospital Italiano de Buenos Aires ]

\section{Referencias}

1. Leuppi JD, Salome CM, Jenkins CR y col. Predictive markers of asthma exacerbation during stepwise dose reduction of inhaled corticosteroid. Am.J.Respir.Crit.Care Med. 2001;163:406412

2. Holgate ST, Davies DE, Lackie PM y col. Ephithelial- mesenchymal interactions in patogenesis of asthma. J Allergy Clin Inmunol. 2000;105: 193-204. 